\title{
33. ALGO MÁS SOBRE LA PRODUCCIÓN CIENTÍFICA DE LOS BOTÁNICOS DE LA EXPEDICIÓN AL VIRREINATO DEL PERÚ (1777-1788).
}

\author{
Antonio GONZÁLEZ BUENO y Raúl RODRÍGUEZ NOZAL
}

En 1996 dimos a las prensas un inventario de los escritos científicos producidos por los botánicos expedicionarios por Perú y Chile'; en estos años hemos localizado un par de textos más que sumar a los consignados entonces.

Ruiz López, H. \& J. Pavón Jiménez. 1801. [MS]. Suplemento â la Quinología, en que se aumentan las Especies de Quina, nuevamente descubiertas en el Perú por $d^{n}$ Juan Tafalla, y la Quina naranjada de $S^{t a}$ Fé con su estampa. Añadese la respuesta á la Memoria de las Quinas de Santa Fé, que insertó d Fran $^{c o}$ Zea en los Anales de Historia natural y la satisfacion á los reparos ô dudas del Ciudadano Jussieu sobre los Géneros del Prodromo de la Flora del Perú y Chile. Pp. I-VI, 1-122.

- Localizado en el Archivo Histórico Nacional, Secc. Consejos, leg. 60827/523.

- En todo similar al texto impreso (Madrid: Viuda e hijo de Marín, 1801). El manuscrito carece del pasaje publicado bajo el epígrafe "Nota" (pp. 115-120), elaborado en respuesta a los comentarios de F.A. Zea contra los autores de la Flora del Perú, que figuran en el artículo "Del Salto de Tequendama" publicado en el cuaderno de los Anales de Historia Natural que vio la luz en febrero de $1801^{2}$.

- Al fin del manuscrito consta la anotación del conde de Ysla, fechada en Madrid, a 12 de enero de 1801: "Imprimase este Suplemento de la Quinologia en que se aumentan las especies de Quina compuesto de sesenta y quatro hojas utiles, con tal de que sea en buen Papel, y se entreguen en los Consejo los exemplares acostumbrados, y uno mas para la Biblioteca de Medicina del Hospital gal."

Ruiz López, H. \& J. Pavón Jiménez. 1802. "Continuación de la carta sobre el estigma del Iris." Diario de Madrid, 331 [27-XI-1802]: 1333-
1334.

-La primera parte, ésta sí referenciada, apareció en un número anterior de este mismo periódico bajo el título "Carta al Editor del Diario sobre un pretendido descubrimiento de Botánica en España"3.

-Sabíamos de la existencia de un manuscrito, bajo el título "Impugnación de la doctrina de Cavanilles sobre los estigmas de Iris", atribuido a H. Ruiz por A.J. Barreiro ${ }^{4}$, quien lo estudió como parte del fondo Joaquín González Hidalgo depositado en la Real Academia de Ciencias, una colección lamentablemente desaparecida tras la Guerra Civil.

-El artículo es una crítica a las "Observaciones botánicas" de A.J. Cavanilles publicadas en los Anales de Ciencias Naturales impresos en noviembre de $1802^{5}$.

\section{Notas}

1. A. González Bueno \& R. Rodríguez Nozal. Huntia, 9(2): 107-132. 1996.

2. F.A. Zea. Anales de Historia Natural, 3(8): 148-160. 1801.

3. H. Ruiz López \& J. Pavón Jiménez. Diario de Madrid, 230 [26-X-1802]: 1329-1331. 1802.

4. A.J. Barreiro (ed.). Relación del Viaje hecho a los Reynos del Perú y Chile por los Botánicos y Dibuxantes enviados por aquella expedición, extractado de los diarios por el orden que llevó en estos su autor Don Hipólito Ruiz. Madrid, 1931. (cf. pág. 500)

5. A.J. Cavanilles. Anales de Ciencias Naturales, 5(15): 245-263. 1802. "Sobre el verdadero estigma del Iris" se ocupa en la segunda de estas "Observaciones..." (cf. págs. 248-249).

Dirección de los autores: A. GONZÁLEZ BUENO. Departamento de Farmacia y Tecnología Farmacéutica. Facultad de Farmacia. Universidad Complutense, E28040 Madrid. e-mail: agbueno@farm.ucm.es. R. RODRÍGUEZ NOZAL. Departamento de Ciencias Sanitarias y Médico-Sociales. Facultad de Medicina. Universidad de Alcalá. e-mail: raulrn@uah.es. 